\title{
Trajetória recente da gestão pública brasileira: um balanço crítico e a renovação da agenda de reformas*
}

\author{
Fernando Luiz Abrucio**
}

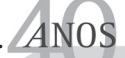

SuMÁRIO: 1. Introdução; 2. Da redemocratização ao governo Lula; 3. Renovação da agenda de reformas: quatro eixos estratégicos.

SUMMARY: 1. Introduction; 2. From redemocratization to the Lula government; 3. Renewal of the reform agenda: four strategic axis.

PALAVRAS-CHAVE: reforma do Estado; gestão pública; profissionalização da burocracia; eficiência; administração por resultados; transparência; trajetória reformista.

KEY WORDS: state reform; public management; bureaucracy professionalization; efficiency; result-based management; transparency; the reformist trajectory.

Este artigo reconstitui, em linhas gerais, a trajetória da administração pública brasileira nos últimos 20 anos, analisando tanto os principais avanços e novidades, quanto os erros de condução das reformas e os problemas de gestão que ainda persistem. Após fazer um balanço que percorre a Nova República, a era Collor, o projeto Bresser e o governo Lula, o texto apresenta uma proposta de quatro eixos estratégicos para a modernização do Estado diante dos desafios do século XXI.

Recent trajectory of the Brazilian public management: a critical assessment and the renewal of the reform agenda

This article retraces, in broad terms, the trajectory of the Brazilian public administration in the last 20 years. It analyzes the main advances and

\footnotetext{
* Artigo recebido e aceito em jun. 2007.

** Doutor em ciência política pela USP, autor de vários textos sobre reforma do Estado no Brasil e no mundo e coordenador do Mestrado e Doutorado em Administração Pública e Governo da Eaesp/FGV. Endereço: Av. Nove de Julho, 2029, 11ํandar - CEP 01313-902, São Paulo, SP, Brasil. E-mail: feabrucio@terra.com.br.
} 
innovations as well as the mistakes made while conducting the reforms and the management issues that still remain. After assessing a period that covers the New Republic, the Collor era, the Bresser project and the Lula government, the article proposes four strategic axis for modernizing the state, facing the challenges of the 21st century.

\section{Introdução}

Um balanço sobre o processo de reforma nos últimos 20 anos revela uma dupla realidade. Por um lado, houve avanços e inovações, em alguns casos deixando raízes mais profundas de modernização. Mas, por outro, constata-se que os resultados foram desiguais e fragmentados para o conjunto do Estado, afora alguns problemas não terem sido devidamente atacados. Separar o joio do trigo desta trajetória reformista é o intuito deste artigo. Com base tanto numa sintética reconstrução histórica quanto nos ideais recentes da nova gestão pública, procura-se aqui ter um olhar crítico sobre o passado recente com vistas à criação de uma agenda efetiva e de longo prazo em torno do tema da gestão pública.

\section{Da redemocratização ao governo Lula}

O processo recente de reforma do Estado no Brasil começou com o fim do período militar. Naquele momento, combinavam-se dois fenômenos: a crise do regime autoritário e, sobretudo, a derrocada do modelo nacional-desenvolvimentista. Era preciso atacar os erros históricos da administração pública brasileira, muitos deles aguçados pelos militares, e encontrar soluções que dessem conta do novo momento histórico, que exigia um aggiornamento da gestão pública.

Entretanto, a principal preocupação dos atores políticos na redemocratização foi tentar corrigir os erros cometidos pelos militares, dando pouca importância à necessidade de se construir um modelo de Estado capaz de enfrentar os novos desafios históricos. De fato, o regime autoritário foi pródigo em potencializar problemas históricos da administração pública brasileira, como o descontrole financeiro, a falta de responsabilização dos governantes e burocratas perante a sociedade, a politização indevida da burocracia nos estados e municípios, além da fragmentação excessiva das empresas públicas, com a perda de foco de atuação governamental.

Diante desses problemas, alterações importantes no desenho estatal brasileiro foram realizadas no final da década de 1980. O principal exemplo disso 
foram as reformas nas finanças públicas, feitas pelo governo Sarney, com destaque para o fim da "conta movimento", do orçamento monetário e a criação da Secretaria do Tesouro Nacional (STN), favorecendo o reordenamento das contas públicas.

Para combater o legado do regime militar, as mudanças mais profundas vieram com a Constituição de 1988. Os constituintes mexeram em várias questões atinentes à administração pública. Entre estas, três conjuntos de mudanças podem ser destacados:

v em primeiro lugar, a democratização do Estado, que foi favorecida com o fortalecimento do controle externo da administração pública, com destaque, entre outras mudanças, para o novo papel conferido ao Ministério Público (MP). Neste aspecto está, também, o reforço dos princípios da legalidade e da publicidade;

v a descentralização foi outra demanda construída nos anos de luta contra o autoritarismo e que ganhou enorme relevância na Constituição de 1988. Após 20 anos de centralismo político, financeiro e administrativo, o processo descentralizador abriu oportunidades para maior participação cidadã e para inovações no campo da gestão pública, levando em conta a realidade e as potencialidades locais. Impulsionadas por esta mudança, várias políticas públicas foram reinventadas e disseminadas pelo país;

v propôs-se, ainda, completar a chamada reforma do serviço civil, por meio da profissionalização da burocracia. Nesta linha, houve ações importantes, como o princípio da seleção meritocrática e universal, consubstanciada pelo concurso público. Em consonância com este movimento, o Executivo federal criou, em 1986, a Escola Nacional de Administração Pública (Enap), num esforço de melhorar a capacitação da alta burocracia.

Todas essas mudanças trouxeram ganhos à administração pública brasileira; porém, o sentido de cada uma delas não se concretizou completamente por conta de uma série de problemas. No que se refere à democratização do Estado, tome-se o exemplo dos tribunais de contas, particularmente os subnacionais, que pouco avançaram no controle dos governantes, quando não estiveram a eles vinculados de forma patrimonialista. A Constituição estabeleceu mecanismos de escolha dos Conselheiros que dificultam a sua autonomia, uma vez que o Executivo tem um enorme poder de interferir neste processo (Arantes et al., 2005).

No caso da descentralização, as dificuldades para potencializá-la foram muitas: houve uma multiplicação exagerada dos municípios, poucos incentivos à cooperação intergovernamental foram estabelecidos, a questão metro- 
politana foi ignorada pela Constituição, além de o patrimonialismo local ter sobrevivido em boa parte do país. Acima de tudo, foi criado um federalismo compartimentalizado (Abrucio, 2005b), em que há mais uma atuação autarquizada dos níveis de governo do que o estabelecimento de laços entre eles. Como a descentralização em um país tão desigual como o Brasil depende da articulação entre os entes federativos, a compartimentalização afeta diretamente (e de forma negativa) os resultados das políticas públicas.

Não obstante as qualidades das medidas em prol da profissionalização do serviço público previstas na Constituição de 1988, parte desta legislação resultou, na verdade, em aumento do corporativismo estatal, e não na produção de servidores do público, para lembrar a origem da palavra (Longo, 2007). Foram criadas falsas isonomias (como a incorporação absurda de gratificações e benefícios) e legislações que tornaram a burocracia mais ensimesmada e distante da população - exemplo claro disso foi o direito irrestrito de greve, que prejudica basicamente os mais pobres. Ademais, estabeleceu-se um modelo equivocado da previdência pública, tornando-a inviável do ponto de vista atuarial e injusta pelo prisma social.

A soma desses aspectos com a crise fiscal do Estado redundou, na década de 1990, num cenário administrativo em que o maior incentivo ao funcionário público estava no final da carreira — a aposentadoria integral —, enquanto seus salários minguavam e crescia a parcela das gratificações no rendimento, as quais dependiam mais da força política de cada setor do que do mérito medido por avaliações de desempenho.

Pouco a pouco, a opinião pública percebeu que a Constituição de 1988 não tinha resolvido uma série de problemas da administração pública brasileira. Esta percepção infelizmente foi transformada, com a era Collor, em dois raciocínios falsos e que contaminaram o debate público: a idéia de Estado mínimo e o conceito de marajás. As medidas tomadas nesse período foram um desastre. Houve o desmantelamento de diversos setores e políticas públicas, além da redução de atividades estatais essenciais. Como o funcionário público foi transformado no bode expiatório dos problemas nacionais, disseminou-se uma sensação de desconfiança por toda a máquina federal, algo que produziu uma lógica do "salve-se quem puder". Foi neste contexto que, paradoxalmente, se constituiu um regime jurídico único extremamente corporativista.

O irônico desta história burlesca de Collor é que, em nome do combate aos marajás e ao "Estado-elefante", seu governo foi marcado pela maior corrupção de todos os tempos no país e pela tentativa de usar o poder estatal para ampliar os tentáculos privados de seu grupo político.

Após o interregno do governo Itamar, que chegou a produzir documentos com diagnósticos importantes sobre a situação da administração pública 
brasileira (principalmente o trabalho organizado por Andrade e Jaccoud, 1993), mas que não teve grande iniciativa reformista, a gestão do presidente Fernando Henrique Cardoso foi bastante ativa. Entre os seus pilares, estava a criação do Ministério da Administração e Reforma do Estado (Mare), comandado pelo ministro Bresser-Pereira. Sua plataforma foi erigida a partir de um diagnóstico que ressaltava, sobretudo, o que havia de mais negativo na Constituição de 1988 e apoiava-se fortemente no estudo e tentativa de aprendizado em relação à experiência internacional recente, marcada pela construção da nova gestão pública.

Bresser foi pioneiro em perceber que a administração pública mundial passava por grandes mudanças, também necessárias no Brasil, mas nem sempre ele soube traduzir politicamente tais transformações para as peculiaridades brasileiras. Este diagnóstico foi exposto de forma clara e profunda no livro Reforma do Estado para a cidadania (1998).

Vale ressaltar os principais avanços obtidos pela chamada reforma Bresser. Em primeiro lugar, a maior mudança realizada foi, paradoxalmente, a continuação e o aperfeiçoamento da civil service reform, por mais que o discurso do Plano Diretor da Reforma do Estado se baseasse numa visão (erroneamente) etapista - com a reforma gerencial vindo depois da burocrática. Houve uma grande reorganização administrativa do governo federal, com destaque para a melhoria substancial das informações da administração pública — antes desorganizadas ou inexistentes - e o fortalecimento das carreiras de Estado. Um número importante de concursos foi realizado e a capacitação feita pela Enap, revitalizada. Em suma, o ideal meritocrático contido no chamado modelo weberiano não foi abandonado pelo Mare; ao contrário, foi aperfeiçoado.

Uma segunda ordem de mudanças diz respeito à área legal, especialmente no campo da reforma constitucional, com as Emendas nos 19 e 20. Medidas que implicaram tetos para o gasto com funcionalismo, alterações no caráter rígido e equivocado do Regime Jurídico Único e introdução do princípio da eficiência entre os pilares do direito administrativo. Tais mudanças constituíram peças essenciais na criação de uma ordem jurídica que estabeleceu parâmetros de restrição orçamentária e de otimização das políticas.

O ministro Bresser também foi responsável por um movimento menos palpável em termos legislativos, e mesmo de difícil mensuração, pois tem efeitos mais de longo prazo. Ele se empenhou obstinadamente na disseminação de um rico debate no plano federal e nos estados sobre novas formas de gestão, fortemente orientadas pela melhoria do desempenho do setor público. Neste sentido, a existência do plano diretor como diretriz geral de mudanças teve um papel estratégico. Esse projeto foi essencial para dar um sentido de agenda às ações, ultrapassando a manifestação normalmente fragmentadora das boas 
iniciativas de gestão. Passados 10 anos, é possível reavaliar certas propostas do plano diretor; porém, o que nos falta hoje é exatamente um plano orientador das reformas na gestão pública.

Bresser se apoiou numa idéia mobilizadora: a de uma administração voltada para resultados, ou modelo gerencial, como era chamado à época. A despeito de muitas mudanças institucionais requeridas para se chegar a este paradigma não terem sido feitas, houve um "choque cultural". Os conceitos subjacentes a esta visão foram espalhados por todo o país e, observando as ações de vários governos subnacionais, percebe-se facilmente a influência destas idéias na atuação de gestores públicos e numa série de inovações governamentais nos últimos anos.

Ademais, a reforma Bresser elaborou um novo modelo de gestão, que propunha uma engenharia institucional capaz de estabelecer um espaço público não-estatal. As organizações sociais (OSs) e as organizações da sociedade civil de interesse público (Oscips) são herdeiras desse movimento — só nos governos estaduais, há cerca de 70 OSs atualmente. O espírito dessa idéia pode ser visto, hoje, nas chamadas parcerias público-privadas (PPPs). Não obstante a inovação conceitual, tais formas deram mais certo nos estados do que na União, sofrendo no plano federal uma enorme resistência ao longo da gestão do ministro Bresser-Pereira.

Para entender os problemas e fracassos da reforma Bresser, é importante analisar o contexto em que ela foi realizada. ${ }^{1}$ Em primeiro lugar, o legado extremamente negativo deixado pela era Collor, período em que houve um desmantelamento do Estado e o serviço público fora desprestigiado. Por conta disso, quando as primeiras propostas da gestão Fernando Henrique Cardoso foram colocadas em debate, grande parte da reação adveio da idéia de que reformar o Estado significaria necessariamente seguir o mesmo caminho "neoliberal" trilhado pelo presidente Collor. O termo reforma do Estado, no fundo, foi ideologizado na disputa política e na produção acadêmica, em boa medida como resultado deste legado inicial da década de 1990.

Um segundo aspecto que influenciou o debate foi o histórico das reformas administrativas no Brasil. Tivemos duas grandes ações neste sentido, ambas em períodos autoritários: o modelo daspiano e o Decreto-Lei $\mathrm{n}^{\circ} 200$. De tal forma que não tínhamos uma experiência democrática de reformismo, baseado no debate, na negociação e num processo decisório menos concentrador.

\footnotetext{
${ }^{1}$ Sobre o processo decisório envolvendo a reforma da gestão pública no período Bresser, consultar também os excelentes trabalhos de Flávio Rezende (2004), de Humberto Falcão Martins (2002) e Valeriano Costa (2002).
} 
Esta inexperiência das elites sociais e políticas brasileiras não barrou todas as reformas, mas foi um empecilho para muitas delas.

Mas o entendimento da proposta Bresser depende da análise de um terceiro aspecto balizador do debate e da luta política nos anos FHC. Trata-se da prevalência da equipe econômica e de seu pensamento na lógica do governo Fernando Henrique. Obviamente que o sucesso inicial da estabilização monetária possibilitou um avanço na discussão reformista, afora ter incluído demandas importantes de transformação do Estado, como a agenda previdenciária. Ademais, não havia uma incompatibilidade natural entre o ajuste fiscal e o Plano Diretor da Reforma do Aparelho do Estado. O que houve, contudo, foi uma subordinação do segundo tópico em relação ao primeiro. Isso ficou bem claro na discussão da Emenda Constitucional no 19 , na qual o aspecto financeiro sobrepujou o gerencial.

A visão economicista estreita da equipe econômica barrou várias inovações institucionais, como a maior autonomia às agências, dado que havia o medo de perder o controle sobre as despesas dos órgãos. Mas havia outras resistências políticas, vindas primordialmente do Congresso. Os parlamentares temiam a implantação de um modelo administrativo mais transparente e voltado ao desempenho, pois isso diminuiria a capacidade de a classe política influenciar a gestão dos órgãos públicos, pela via da manipulação de cargos e verbas. Ademais, também havia senões no núcleo central do governo, sob a influência do ministro chefe da Casa Civil, Clóvis Carvalho, o que levou o Palácio do Planalto a não apostar numa reforma administrativa mais ampla.

Nesse contexto, o Mare não teve a capacidade de coordenar o conjunto do processo de reforma do Estado. O melhor exemplo de um tema que escapou ao alcance da reforma Bresser foi o das agências regulatórias, montadas de forma completamente fragmentada e sem uma visão mais geral do modelo regulador que substituiria o padrão varguista de intervenção estatal. O fracasso desta estratégia ficou claro, por exemplo, no episódio do "apagão", que teve grande relação com a gênese mal resolvida do marco regulatório no setor elétrico.

O fato é que muitas alterações importantes no desenho estatal e nas políticas públicas sob o governo FHC passaram ao largo da agenda da gestão pública proposta pelo ministro Bresser-Pereira. Não se trata de dizer que as idéias colocadas pelo plano diretor estavam todas corretas, o que não é verdadeiro. Mas é preciso fazer com que a agenda de reforma da gestão pública tenha um caráter transversal, capaz de estabelecer um novo paradigma administrativo ao país - e isso o projeto de Bresser proporcionava em maior medida do que a visão da equipe econômica.

Não há dúvidas de que as condições políticas prejudicaram a reforma Bresser. Contudo, ela também continha erros de diagnóstico. Um deles se rela- 
ciona com o conceito muito restrito de carreiras estratégicas de Estado, tanto para o governo federal quanto para o contexto federativo. Ao delimitar o núcleo estratégico em poucas funções governamentais, basicamente ligadas à diplomacia, às finanças públicas, à área jurídica e à carreira de gestores governamentais, o projeto da reforma Bresser deixou de incorporar outros setores essenciais da União, fundamentais para que ela atue como reguladora, avaliadora e indutora no plano das relações intergovernamentais.

Dois exemplos revelam bem o problema da definição restrita feita pelo plano diretor: a função de defesa agropecuária e a tarefa de proteção do meio ambiente, que ficaram de fora da proposta original. No primeiro caso, como ficou claro no episódio da febre aftosa, o governo federal tem um papel importante para garantir uma das principais molas da economia brasileira, o setor agropecuário. Já o meio ambiente é um bem público estratégico para o desenvolvimento brasileiro, e os governos subnacionais, especialmente na Região Amazônica, não têm condições de resguardá-lo sozinhos.

Além disso, a definição de carreira estratégica válida para a União não deve ser a mesma para os governos estaduais e municipais, uma vez que as funções básicas são bem distintas. Não obstante esta incorreção, cabe frisar que a reforma Bresser tinha toda a razão em atuar em prol de uma burocracia estratégica, de modo que o núcleo básico tivesse um status diferenciado em relação ao restante do funcionalismo, como tem ocorrido em todo mundo. Assim, certas funções que não constituem o núcleo do Estado podem ser realizadas por funcionários terceirizados, ou suas funções podem ser repassadas para entes privados, ao passo que as atividades essenciais precisam de um corpo meritocrático constantemente capacitado e com maior estabilidade funcional. É por esta razão que a noção de emprego público, regido pela CLT e diferente do modelo estatutário (necessário para as carreiras estratégicas), deve ser resgatada da maneira que fora enunciada pela Emenda no 19 .

Um segundo erro de diagnóstico da reforma Bresser foi estabelecer, em boa parte do debate, uma oposição completa entre a chamada administração burocrática e as novas formas de gestão. Esta visão etapista é, em primeiro lugar, contraproducente, dado que gera um atrito desnecessário com setores da burocracia estratégica que poderiam ser conquistados mais facilmente para o processo de reformas. Além disso, a perspectiva dicotômica leva a crer que "uma etapa substitui a outra". Ao contrário, trata-se mais de um movimento dialético em que há, simultaneamente, incorporações de aspectos do modelo weberiano e a criação de novos instrumentos de gestão.

Desse modo, a nova gestão pública tem uma série de peculiaridades que dizem respeito à necessidade de se ter instrumentos gerenciais e democráticos novos para combater os problemas que o Estado enfrenta no mundo contem- 
porâneo. Se o formalismo e a rigidez burocrática devem ser atacados como males, alguns alicerces do modelo weberiano podem, porém, constituir uma alavanca para a modernização, principalmente em prol da meritocracia e da separação clara entre o público e o privado.

Em suma, a reforma Bresser não teve força suficiente para sustentar uma reforma da administração pública ampla e, principalmente, contínua. $\mathrm{O}$ legado negativo do período Collor, a pouca importância dada ao tema por parte do núcleo central do poder e as resistências da área econômica criaram obstáculos ao projeto do plano diretor. Não se pode esquecer, ainda, da oposição petista à reforma, movida pelo peso do corporativismo dentro do partido e por uma estratégia de tachar qualquer reforma da era FHC como "neoliberal". Além disso, a sociedade estava fortemente mobilizada pelas questões da estabilidade monetária e da responsabilidade fiscal, e os principais atores políticos e sociais não deram o mesmo status ao tema da gestão pública.

A reforma da gestão pública, ademais, enfrentou um problema estrutural: boa parte do sistema político tem um cálculo de carreira que bate de frente com a modernização administrativa. Profissionalizar a burocracia e avaliá-la constantemente por meio de metas e indicadores são ações que reduziriam a interferência política sobre a distribuição de cargos e verbas públicas. Esta situação só pode ser mudada com a conscientização da sociedade e de uma elite da classe política sobre os efeitos negativos do nosso "patrimonialismo profundo".

O segundo governo FHC, mesmo tendo incorporado algumas conquistas da reforma Bresser, começou com a extinção do Mare e foi marcado, na maior parte do tempo, pelo empobrecimento da agenda da gestão pública. Decerto que os avanços na área fiscal representavam continuidade com as reformas anteriores. Também houve inovações vinculadas à sistemática de planejamento, centradas no PPA (plano plurianual), embora este tenha avançado mais em termos de programação orçamentária do que nos de programação das políticas públicas - não por acaso, o PPA hoje funciona mais como um "OPA" ("orçamento plurianual"). De qualquer modo, os primeiros três anos do segundo mandato foram caracterizados pela ausência de uma estratégia de gestão pública.

Um panorama dos caminhos da gestão pública brasileira desde a redemocratização não pode ficar apenas na dinâmica diacrônica e cronológica. Houve uma série de ações inovadoras que não ficaram circunscritas a um dos períodos governamentais em análise. Seus impactos, entretanto, foram fragmentados e dispersos, sem que por isso fossem menos importantes. Destaque aqui deve ser dado a cinco movimentos. 
v O mais importante movimento foi montado em torno da questão fiscal. Ele conseguiu vários avanços, alguns interligados com a agenda constituinte e outros com a proposta Bresser. Seu corolário foi a aprovação da Lei de Responsabilidade Fiscal. Na verdade, esta coalizão trouxe enormes ganhos de economicidade ao Estado brasileiro, mas não teve tanto sucesso no que se refere à eficiência (fazer mais com menos). A agenda da eficiência vai exigir ações de gestão pública, algo cuja importância os economistas, membros majoritários desse grupo, ainda não compreenderam. Para tanto, terão de conhecer melhor os mecanismos da nova gestão pública.

、 Os governos estaduais e, principalmente, os municipais introduziram diversas novidades no campo das políticas públicas: maior participação social, ações mais ágeis, e, no caso específico dos estados, a expansão dos centros de atendimento integrado, uma das maiores revoluções na administração pública brasileira contemporânea. Mesmo assim, há uma enorme heterogeneidade entre esses níveis de governo, com uma grande parcela deles ainda vinculada ao modelo burocrático tradicional ou, pior, a formas patrimoniais - ou, ainda, a uma mistura estranha, mas comum, de ambos os modelos.

、 Ocorreram também diversas inovações nas políticas públicas, particularmente as vinculadas à área social. Mecanismos de avaliação, formas de coordenação administrativa e financeira, avanço do controle social, programas voltados à realidade local e, em menor medida, ações intersetoriais aparecem como novidade. Saúde, educação e recursos hídricos constituem as áreas com maior transformação. É bom lembrar que uma das políticas mais interessantes na área social, os programas de renda mínima acoplados a instrumentos criadores de capacidade cidadã, teve origem nos governos subnacionais e não na União.

v Constituiu-se uma coalizão em torno do PPA e da idéia de planejamento, não na sua versão centralizadora e tecnocrática adotada no regime militar, mas, sim, segundo uma proposta mais integradora de áreas a partir de programas e projetos. Embora o PPA esteja mais para um "OPA" na maioria dos governos, alguns estados trouxeram inovações importantes, como a regionalização e a utilização de indicadores para nortear o plano plurianual.

v Talvez a ação reformista mais significativa na gestão pública brasileira tenha sido o governo eletrônico. Impulsionado pela experiência do governo estadual de São Paulo, ele se espalhou por outros estados, capitais e governo federal. Sua disseminação é impressionante. Seus resultados são excelentes em termos de organização das informações. Mais importante ainda, 
a tecnologia da informação tem levado à redução dos custos, bem como ao aumento da transparência nas compras governamentais, reduzindo o potencial de corrupção. O ponto em que houve menor avanço do governo eletrônico é exatamente na maior interatividade com os cidadãos, em prol da maior accountability.

O governo Lula continuou uma série de iniciativas advindas da experiência anterior da modernização do Estado brasileiro, particularmente no reforço de algumas carreiras, no campo do governo eletrônico e na nova moldagem que deu à Controladoria Geral da União, hoje um importante instrumento no combate à ineficiência e à corrupção. Além disso, aproveitou sua inspiração na democracia participativa para discutir mais e melhor o PPA com a sociedade, em várias partes do Brasil, realizando um avanço no campo do planejamento. Só que a experiência petista no plano local, com vários casos de sucesso, tem sido menos aproveitada do que se esperava, infelizmente. Claro que é difícil avaliar um período governamental que ainda não acabou, mas alguns pontos podem ser ressaltados.

O ponto mais visível da presidência Lula no campo da administração pública tem sido, até agora, sua incapacidade de estabelecer uma agenda em prol da reforma da gestão pública. Definitivamente, este não tem sido um tema-chave do atual governo, um erro grave para quem tem o objetivo declarado de aumentar a efetividade das políticas públicas, notadamente as sociais, sem prejudicar o necessário ajuste fiscal. Não surpreende, portanto, a constante veiculação pela imprensa de exemplos de falhas gerenciais.

A pior característica do modelo administrativo do governo Lula foi o amplo loteamento dos cargos públicos, para vários partidos e em diversos pontos do Executivo federal, inclusive com uma forte politização da administração indireta e dos fundos de pensão. Este processo não foi inventado pela gestão petista, mas sua amplitude e vinculação com a corrupção surpreendem negativamente por conta do histórico de luta republicana do Partido dos Trabalhadores. Se houve algo positivo na crise política de 2005 é que, depois do conhecimento pelo grande público do patrimonialismo presente em vários órgãos da administração direta e em estatais, tornou-se mais premente o tema da profissionalização da burocracia brasileira.

Ao mesmo tempo que abre as portas da administração pública à politização, o governo Lula deixa como legado positivo o aperfeiçoamento de alguns importantes mecanismos de controle da corrupção. As ações da Polícia Federal e, principalmente, o trabalho da Controladoria Geral da União são inegáveis avanços da gestão petista que devem ser definitivamente incorporados pelo Estado brasileiro. 
Outra experiência bem-sucedida no campo da gestão pública no governo Lula se deu no plano federativo, representada por duas ações: o Programa Nacional de Apoio à Modernização da Gestão e do Planejamento dos Estados e do Distrito Federal (Pnage) e o Programa de Modernização do Controle Externo dos Estados e Municípios Brasileiros (Promoex). Esses projetos têm como objetivo modernizar a administração pública das instâncias subnacionais, particularmente no nível estadual. ${ }^{2}$

O Pnage e o Promoex não são os primeiros programas de modernização das instituições subnacionais comandados pelo governo federal. No governo FHC houve o avanço do Programa Nacional de Apoio à Administração Fiscal para os Estados Brasileiros (Pnafe), que teve um caráter pioneiro no auxílio aos governos estaduais na área financeira. No entanto, os dois programas supracitados são diferentes, em razão de tratarem basicamente da temática da gestão pública. Depois de duas décadas de reformas nas quais a redução do aparato e dos gastos estatais constituiu o fio condutor do processo, o Pnage e o Promoex priorizaram a reconstrução da administração pública em suas variáveis vinculadas ao planejamento, aos recursos humanos, à sua interconexão com as políticas públicas e ao atendimento dos cidadãos.

Os resultados dos programas Pnage/Promoex não podem ser avaliados ainda, porque sua implementação está truncada — em grande parte, por conta da miopia fiscalista da área fazendária. Mesmo assim, vale destacar três qualidades do projeto. Em primeiro lugar, a proposta de um programa nacional para a heterogênea federação brasileira, fazendo com que a União realize seu papel de indutor de mudanças. Uma segunda qualidade está vinculada à realização de um amplo diagnóstico antes da proposição de modelos fechados aos estados. Dessa maneira, evitou-se a lógica "solução em busca de problemas" que alimentou algumas reformas induzidas pelo governo federal no período FHC. Por fim, o maior avanço do Pnage/Promoex foi construir tais programas por meio de ampla participação e discussão com os estados e tribunais de contas. Este modelo intergovernamental e interinstitucional é mais participativo e funciona mais em rede do que de forma piramidal. Sua concepção é a mais adequada para implementar ações administrativas numa federação, em nítido contraste com a (nefasta) tradição centralizadora do Estado brasileiro.

A criação do Conselho de Desenvolvimento Econômico e Social (CDES), mais conhecido como "Conselhão", foi outra idéia interessante do governo Lula. Este órgão poderia ser um articulador de alianças e coalizões sociais em torno de reformas e temas prioritários para o Brasil. Porém, sua implementa-

\footnotetext{
${ }^{2}$ Para uma descrição mais detalhada desses programas, ver Abrucio (2005b).
} 
ção não teve o sucesso esperado. Isto ocorreu, em primeiro lugar, porque em vez de o CDES centrar o foco em apenas algumas questões, sua agenda tem sido muito pulverizada. Cabe ressaltar que quando todos os assuntos são pautados na mesma intensidade por um governo, este não tem prioridades claras, o que afeta negativamente seu desempenho. Esta característica, na verdade, é válida para várias das ações da gestão petista. Como defeito mais grave, as decisões do "Conselhão" praticamente não tiveram impacto sobre a formulação das políticas públicas. Seu papel foi mais o de receber sugestões da sociedade do que o de montar uma rede mais efetiva com setores sociais para influenciar e/ou fortalecer uma agenda reformista.

Eleito por um discurso em prol de uma ampla transformação da sociedade brasileira, o presidente Lula acreditava que bastava vontade política para mudar o país. A esta visão voluntarista se somou a ausência de um projeto de reforma do Estado, pois o PT, até há pouco tempo, enxergava em qualquer projeto neste sentido uma natureza "neoliberal" - em outras palavras, um "pecado". Resultado: muitas das promessas eleitorais não puderam ser cumpridas porque a gestão pública não estava preparada para atingir os fins propostos.

É bem verdade que o governo Lula está colhendo bons resultados em certas áreas de políticas públicas. E tais resultados derivam em parte de uma boa estratégia de gestão. O trabalho do Ministério do Desenvolvimento Social, por exemplo, está ancorado num conjunto competente de técnicos e numa estratégia de monitoramento bem formulada. Tal qual este caso, há alguns outros em que a variável gestão tem sido estratégica. Contudo, são experiências excepcionais e fragmentadas. Mais uma vez, volta-se à questão-chave dos últimos 20 anos: a falta de uma visão integrada e de longo prazo para a gestão pública brasileira.

\section{Renovação da agenda de reformas: quatro eixos estratégicos}

A renovação da agenda reformista passa pela definição de quais são as questões centrais para a modernização do Estado brasileiro. Nesta linha de raciocínio, propomos aqui quatro eixos estratégicos: profissionalização, eficiência, efetividade e transparência/accountability.

No que tange à profissionalização da burocracia, há cinco questões importantes que devem nortear a modernização administrativa. A primeira se refere à redução dos cargos em comissão. A crise política do governo Lula em 2005 foi impulsionada não só pelo problema do financiamento de campanhas, mas principalmente pela briga por importantes postos nas estatais federais estavam em jogo o enorme poder dos Correios e, sobretudo, do IRB. O fato é que não é possível ter, em pleno século XXI, mais de 20 mil cargos comissionados 
na administração direta e incontáveis indicações políticas nas empresas do governo e nos fundos de pensão. Obviamente, o presidente eleito precisa contar com um número de cargos para repassar aos responsáveis pela implementação de seu plano de governo, democraticamente aprovado pelas urnas. Todavia, o montante de indicações de livre provimento por parte do Executivo federal brasileiro não encontra paralelo em nenhum país desenvolvido, abrindo brechas para a corrupção.

A profissionalização do alto escalão governamental é condição sine qua non para o bom desempenho das políticas públicas. Uma parte importante destes cargos deve ser preenchida necessariamente pela burocracia estatal, sendo que os agentes políticos devem escolher, na maioria das vezes, os funcionários de carreira que devem ocupar tais postos. Para tanto, este processo deve ser transparente, com a ampla divulgação do currículo dos servidores escolhidos, e sofrer controle ininterrupto - neste diapasão, a idéia do exministro Márcio Thomaz Bastos de acompanhar a evolução patrimonial e as contas de tais funcionários foi uma excelente medida.

Só que há uma parcela dos cargos públicos que deve ser preenchida por gente de fora da máquina pública, não apenas porque o eleito precisa colocar pessoas de sua confiança e que compartilhem de suas idéias no alto escalão governamental. É interessante também trazer profissionais do mercado e da academia para "oxigenar" a administração pública e incorporar novas técnicas e conhecimentos. Isto já vem sendo feito, mas tais escolhas poderiam ser mais transparentes e mesmo competitivas - este último quesito valeria principalmente para o preenchimento de postos nas estatais. A abertura de edital para envio de currículos, por exemplo, permitiria uma caça aos talentos capaz de melhorar a gerência do Estado, além de mudar a péssima imagem que a sociedade tem do governo.

A profissionalização da burocracia federal passa, ainda, pela redefinição e fortalecimento das carreiras estratégicas de Estado. Como argumentado anteriormente, é preciso incluir outras áreas que ficaram originalmente de fora da lista proposta pelo plano diretor, tendo como parâmetro as funções que a União não pode simplesmente descentralizar — embora possa compartilhar para outros entes ou repassar para o mercado. Os corpos burocráticos selecionados nesta categoria devem ser aqueles que têm papel-chave nas políticas, e não os funcionários intermediários ou que realizam atividades auxiliares qualquer "carreirão", como aparece em certas demandas corporativistas, seria um desastre. No bojo desta transformação, é preciso transferir algumas tarefas aos estados e municípios que ainda continuam inadequadamente com o governo federal - atividades-fim na saúde, por exemplo, só podem ser de atribuição dos governos subnacionais. 
Um quarto aspecto referente à profissionalização diz respeito ao aumento do investimento em capacitação dos servidores públicos. Este treinamento, ademais, deve estar vinculado a um projeto mais amplo e integrado de modernização da administração pública. Diante das enormes desigualdades da federação brasileira, a União terá de ser indutora e parceira dos estados e municípios neste processo de remodelagem da burocracia. A favor deste último argumento, cabe lembrar um dos paradoxos básicos das políticas públicas no Brasil: elas são, em sua maioria, realizadas no plano local, exatamente onde as capacidades gerenciais e burocráticas são menos desenvolvidas.

A construção de um novo relacionamento entre o Estado e os sindicatos dos servidores públicos completa o quadro da profissionalização. Neste quesito, a questão mais premente é a regulamentação do direito de greve, dandolhe um caráter mais próximo da negociação coletiva, com direitos e deveres mútuos para o governo e para os funcionários. Evita-se, assim, que a população mais pobre seja a grande perdedora nas paralisações, mas também seriam garantidos padrões estáveis de horizonte profissional para a burocracia. A importância deste tema não está apenas na necessidade de oferecer melhores serviços públicos. Mais do que isso, é preciso recuperar a imagem da burocracia junto à sociedade, muito manchada pela irresponsabilidade de certos movimentos grevistas.

O segundo eixo estratégico é o da eficiência. Aqui, uma questão-chave é a mudança na lógica do orçamento, hoje marcada pelo descompasso entre o planejamento mais geral de metas e a forma como a peça é elaborada e executada anualmente. No campo da elaboração, deve-se atacar tanto o caráter "engessado" da maior parte das despesas, quanto as ações extremamente fragmentadas originadas das emendas parlamentares. No fundo, são duas faces da mesma moeda, pois a definição de um grande número de gastos obrigatórios deriva da desconfiança em relação ao emendismo parlamentar, e este se torna uma válvula de escape para que os congressistas tenham algum poder de decisão orçamentária. A irracional soma destes dois aspectos produz um resultado básico: os partidos e, especificamente, o Legislativo tornam-se incapazes de definir uma agenda programática e sistêmica de políticas governamentais.

O processo orçamentário brasileiro também é caracterizado pela enorme liberdade que o Executivo tem para executar os gastos, com grande autonomia em relação ao que fora decidido no Legislativo - por isso, o orçamento aprovado torna-se autorizativo, e não impositivo. Isso é feito por meio do uso constante (e abusivo) do contingenciamento das verbas. Este instrumento é totalmente controlado pelo Ministério da Fazenda, que segue à risca sua lógica fiscalista, com pouca articulação com o que ocorre em cada política pública. Ora, metas governamentais só podem ser efetivamente perseguidas, com 
monitoramento e avaliação adequados, se houver certa regularidade na alocação das despesas públicas, algo que o contingenciamento torna muito difícil, reduzindo, assim, as chances de aumentar a eficiência da máquina pública.

O governo eletrônico é o instrumento com maior potencial para elevar a eficiência governamental no Brasil. Muito já se avançou neste terreno, o que garante um alicerce para a continuidade das ações. Mas ainda há várias áreas do Estado que não foram "iluminadas" pelo chamado e-government, particularmente os "cartórios governamentais", que são os órgãos avessos à transparência e a qualquer controle público. É preciso utilizar o governo eletrônico, ademais, em pontos em que já se faz presente, como é o caso das licitações públicas, que deveriam ser predominantemente baseadas em compras eletrônicas. Só que não basta tornar mais transparente o momento da escolha dos fornecedores ou executores de serviços públicos. É igualmente necessário permitir um acompanhamento, em tempo real, da execução de tais despesas.

A eficiência, além de reduzir gastos governamentais, pode otimizar os recursos à disposição tanto do Estado quanto dos cidadãos. No primeiro caso, por meio de parcerias público-privadas (PPPs) e formas de concessão que alavanquem a capacidade de investimento dos níveis de governo. Esta trilha reformista é importante para realçar que a atuação conjunta ou o repasse de tarefas ao setor privado pode ser uma maneira de fortalecer a ação governamental, em vez de enfraquecê-la. Em outras palavras, é preciso superar o debate privatismo versus estatismo.

Pelo ângulo da sociedade, políticas de desburocratização podem reduzir os custos das atividades estatais e, ao mesmo tempo, melhorar a vida da população, reduzindo seus custos de transação para obter serviços públicos. Esta é uma linha de atuação que foi iniciada com o ministro Hélio Beltrão, ainda na ditadura militar, e que nenhum governo da redemocratização tornou prioridade. Cabe reforçar que desburocratizar não só aumenta a eficiência como combate a corrupção e, principalmente, coloca os cidadãos em pé de igualdade, exatamente num país em que a desigualdade começa pelo acesso ao Estado - é a marca do chamado personalismo em nossa história.

A efetividade é outro eixo fundamental para uma visão de gestão de longo prazo, uma vez que as políticas públicas cada vez mais têm seu desempenho avaliado pelos resultados efetivos que trazem aos cidadãos. Por exemplo, o norte da efetividade é reduzir a criminalidade, e não multiplicar presídios. Desse modo, para além da eficácia - constituída pelos produtos da ação governamental —, a ação efetiva é mensurada por indicadores de impacto.

A gestão por resultados é hoje a principal arma em prol da efetividade das políticas públicas. Para tanto, é preciso orientar a administração pública por metas e indicadores. Embora estes já tenham sido introduzidos em algu- 
mas experiências brasileiras, o seu uso ainda é bem restrito, pouco conhecido do público e, pior, de pequena assimilação junto à classe política. Esta revolução gerencial dependerá, portanto, de um convencimento dos diversos atores políticos e sociais sobre a necessidade de se adotar este novo modelo de gestão. Daí que não bastarão alterações institucionais; serão necessárias mudanças na cultura política, como ocorreu no caso da responsabilidade fiscal.

A lógica segmentada das políticas públicas deve igualmente sofrer uma transformação. Ações intersetoriais e programas transversais devem ser priorizados. Para tanto, será necessário atacar a aliança entre políticos e burocratas em torno do atual modelo administrativo fragmentador. Para ambos, o fracionamento dos ministérios e secretarias aumenta o poderio político de cada área, criando nichos monopolistas de poder. O governo se torna, assim, um conjunto de "caixinhas" com pouca comunicação entre si. Mesmo a adoção do PPA não mudou isto. Quando há medidas mais efetivas contra esta fragmentação organizacional, elas partem de uma estrutura coordenadora normalmente escolhida pelo governante máximo - presidente, governador ou prefeito. Só que este órgão coordenador não consegue atingir a totalidade da administração pública — na verdade, afeta somente uma pequena parte. O caso do Brasil em Ação, na gestão de Fernando Henrique Cardoso, e os primeiros resultados do PAC, na era Lula, demonstram cabalmente que a falta de coordenação intragovernamental condena parte do Estado a ser regularmente pouco efetivo.

Ainda no campo da coordenação, a efetividade das políticas públicas depende muito hoje do entrosamento entre os níveis de governo, uma vez que os entes locais executam as ações, mas precisam de colaboração horizontal e vertical para ter sucesso. Porém, no mais das vezes, a cooperação federativa é frágil e há poucos incentivos institucionais a seu favor. Nas áreas em que as relações intergovernamentais são mais azeitadas, as políticas geralmente são mais bem-sucedidas, e vice-versa. O caso da saúde faz parte do primeiro grupo e o da segurança, do segundo (e fracassado) time. Esta questão, portanto, é estratégica para se alcançar maior efetividade governamental.

O fortalecimento da regulação dos serviços públicos é outro ponto fundamental em prol de um governo mais efetivo. Como muitas tarefas antes realizadas pelo Estado foram repassadas ao setor privado ou mesmo ao terceiro setor, mas continuam sob supervisão estatal, é preciso ter marcos e aparatos regulatórios que funcionem a contento. Regular bem, é bom ressaltar, significa não só garantir o caráter público dos serviços, mas também a sua qualidade - $\mathrm{e}$ nenhum ente privado ou ONG fará melhor que o Estado caso não seja regulado.

Aumentar a transparência e a responsabilização do poder público constitui o último eixo estratégico desta agenda de reformas. Nos últimos anos, muito se avançou no Brasil em termos de democratização do Estado. Mas é 
necessário aprofundar este processo, pois a administração pública brasileira só será mais eficiente e efetiva caso possa ser cobrada e controlada pela sociedade.

Os vários escândalos recentes desgastaram a imagem do Estado brasileiro e, por isso, a população só tenderá a participar mais do controle social se houver avanços no combate à corrupção. Transparência e punição dos envolvidos são duas medidas que resgatariam o sentimento cívico da imensa maioria dos cidadãos desenganados ou apáticos.

O Brasil criou uma série de instrumentos e arenas participativas capazes de estabelecer controle político e social dos agentes governamentais. Talvez possam ser montados mais alguns ou disseminados outros para localidades que não os tenham. Mas o problema maior do caso brasileiro é fazer valer o que já existe. Tribunais de contas, conselhos de políticas públicas e ouvidorias precisam cumprir seus papéis institucionais onde não são efetivos — e na maior parte do país infelizmente esta é a realidade.

A lógica do sistema político, ademais, pouco contribui para o controle social dos representantes e dos governos. O Brasil é recordista em amnésia eleitoral. A maior parcela do eleitorado - cerca de 70\% — não lembra em quem votou nos pleitos legislativos. Os partidos são muito distantes dos cidadãos, pois a maioria não realiza prévias ou primárias. Pior do que isso: parte significativa das legendas constitui apenas um veículo eleitoral para políticos personalistas, algo que se consubstancia na prática perversa e intensa do troca-troca partidário. Decerto que a democracia brasileira avançou muito nos últimos anos, mas a frágil conexão entre eleitores e eleitos favorece o clientelismo e o patrimonialismo em várias instâncias de poder, sobretudo no plano subnacional. Daí que a manutenção do atual sistema político reforça as piores características do modelo administrativo. É preciso mexer no primeiro para modernizar as profundezas da gestão pública.

Com o intuito de fazer uma modernização democratizadora - e não meramente tecnocrática - do Estado, fóruns como o chamado "Conselhão" podem ser incentivados, para que cumpram o papel de levar demandas e propostas da sociedade para o debate com os formuladores de políticas públicas. Só que a maior parte da sociedade, inclusive os setores mais organizados, carece de boas informações e análises sobre a qualidade da administração pública. É preciso criar entidades sociais independentes que aumentem e disseminem o conhecimento sobre as ações e os impactos dos programas governamentais. E aqui o papel dos acadêmicos, dos intelectuais e, em suma, da universidade, tem de ser maior do que é atualmente. Isso é válido tanto para entender de forma sistemática e sistêmica as políticas públicas, quanto para repassar à população, de maneira acessível, indicadores e alternativas de políticas. 
Uma agenda de longo prazo para reformar a gestão pública brasileira depende, como em qualquer outro campo de políticas públicas, não só de idéias e análises. Acima de tudo, é preciso constituir coalizões. Atores estratégicos precisam ser convencidos da centralidade dessa questão, como já o foram em outros tópicos. A importância dada ao tema por novos governantes, como Aécio Neves com o seu "choque de gestão", é um alento. Mas o assunto ainda não ganhou dimensão política capaz de levá-lo ao centro do debate. Eleições constituem um momento fulcral para impulsionar novas alianças em torno de determinadas questões. Veremos se isso irá ocorrer ou não no pleito municipal em 2008 e, principalmente, na disputa presidencial de 2010. Os formadores de opinião terão um papel central para sedimentar — ou não — este caminho. E, para que os estudiosos de administração pública influenciem este processo, eles precisam, urgentemente, produzir mais pesquisas e publicações acerca do passado recente e das possibilidades de reforma do Estado brasileiro. Este artigo é um convite para que mais colegas se juntem a esta empreitada, aprofundando o entendimento das questões aqui colocadas.

\section{Referências bibliográficas}

ABRUCIO, Fernando Luiz. A cooperação federativa no Brasil: a experiência do período FHC e os desafios do governo Lula. Revista de Sociologia Política, Curitiba: Universidade Federal do Paraná, n. 24, p. 41-67, jul. 2005a.

Reforma do Estado no federalismo brasileiro: a situação das administrações públicas estaduais. Revista Brasileira de Administração Pública, Rio de Janeiro: FGV, v. 39, n. 2, p. 401-420, mar./abr. 2005b.

; LOUREIRO, Maria Rita (Orgs.). O Estado numa era de reformas: os anos FHC. Brasília: Ministério do Planejamento/Pnud/OCDE, 2002.

ANDRADE, Régis de Castro; JACCOUD, Luciana (Orgs.). Estrutura e organização do Poder Executivo. Brasília: Enap/Pnud, 1993.

ARANTES, Rogério Bastos; ABRUCIO, Fernando Luiz; TEIXEIRA, Marco Antonio Carvalho. A imagem dos tribunais de contas subnacionais. Revista do Serviço Público, Brasília: Enap, v. 56 , n. 1 , p. $57-85,2005$.

BRESSER-PEREIRA, Luiz Carlos. Reforma do Estado para a cidadania. São Paulo: 34, 1998.

COSTA, Valeriano Mendes Ferreira. A dinâmica institucional da reforma do Estado: um balanço do período FHC. In: ABRUCIO, Fernando Luiz; LOUREIRO, Maria Rita (Orgs.). O 
Estado numa era de reformas: os anos FHC. Brasília: Ministério do Planejamento/Pnud/ OCDE, 2002.

LONGO, Francisco. Mérito e flexibilidade: a gestão das pessoas no setor público. São Paulo: Fundap, 2007.

MARTINS, Humberto Falcão. Reforma do Estado e coordenação governamental: as trajetórias das políticas de gestão pública na era FHC. In: ABRUCIO, Fernando Luiz; LOUREIRO, Maria Rita (Orgs.). O Estado numa era de reformas: os anos FHC. Brasília: Ministério do Planejamento/Pnud/OCDE, 2002.

REZENDE, Flávio da Cunha. Por que falham as reformas administrativas? Rio de Janeiro: FGV, 2004. 